\title{
A investigação da prática de monitores em um observatório astronômico: subsídios para a formação
}

The investigation of the practice of monitors in an astronomical observatory: contributions to the training

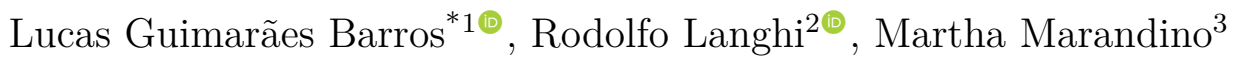 \\ ${ }^{1}$ Universidade Estadual Paulista, Faculdade de Ciências, Programa de Pós-Graduação em Educação para a Ciência, São Paulo, \\ SP, Brasil \\ ${ }^{2}$ Universidade Estadual Paulista, Faculdade de Ciências, Departamento de Física, Programa de Pós-Graduação em Educação \\ para a Ciência, São Paulo, SP, Brasil \\ ${ }^{3}$ Universidade de São Paulo, Faculdade de Educação, Programa de Pós-Graduação Interunidades em Ensino de Ciências, São \\ Paulo, SP, Brasil
}

Recebido em 23 de Outubro, 2017. Revisado em 13 de Fevereiro, 2018. Aceito em 13 de Fevereiro, 2018.

\begin{abstract}
A presente pesquisa está centrada no estudo sobre a formação de monitores em espaços de divulgação da Astronomia, tendo como objetivo principal elencar elementos pertinentes à formação de monitores a partir de uma experiência em um observatório astronômico local. Para isso, utilizou-se questionários, entrevistas semiestruturadas e observação das atividades de campo dos monitores, tomando-se como referencial de análise dos dados a Análise de Conteúdo. Dentre os resultados encontrados, percebeu-se o aspecto motivador da monitoria encontrado nas atividades de divulgação, além das experiências oriundas dessa atuação. Foram mapeadas também algumas dificuldades concernentes à interação do monitor com o público e com a equipe, a predominância de uma formação focada na interação entre monitor veterano e monitor novato, além de experiências advindas da prática da monitoria no local, permitindo a delimitação de um conjunto de elementos que viriam a constituir o perfil do monitor nesses locais.

Palavras-chave: Formação de monitores, Divulgação científica, Ensino de Astronomia, Educação Não Formal, Ensino de Ciências.
\end{abstract}

\begin{abstract}
The present research is focused in the study about the training of monitors in communication of astronomy, having as main objective to point relevant elements to the training of monitors from an experience in a local astronomical observatory. For this, we used questionnaires, semi-structured interviews and observation of the field activities of the monitors, taking as a reference the data analysis the content analysis. Among the findings, it was noticed the motivating aspect of monitoring found in outreach activities, in addition to the experiences from this rule. Were also mapped some difficulties concerning the monitor interaction with the public and with the staff, the predominance of training focused on interaction between veteran monitor and beginner monitor, in addition to experiences from the practice of monitoring in place, allowing the delimitation of a set of elements that would constitute the monitor profile in these locations.
\end{abstract}

Keywords: Training of monitors, Scientific communication, Astronomy Education, Non Formal Education, Science Teaching.

\section{Introdução}

A presente pesquisa está centrada no estudo sobre a formação de monitores em espaços de divulgação da Astronomia. Este tema, inserido em um amplo contexto que contempla a educação não formal e a divulgação científica, vem adquirindo cada vez mais espaço na literatura de pesquisa em ensino de ciências [1-4], embora ainda se note escassez de produções quando comparadas com outras linhas de pesquisas, presentes em linhas temáticas dos principais eventos da área ${ }^{1}$

*Endereço de correspondência: lucas.gbarros100@gmail.com

1 Exemplos de eventos da área: Encontro Nacional de Pesquisa em Educação em Ciências (ENPEC), Encontro de Pesquisa em Ensino
Por apresentar uma estrutura diferenciada de locais como a escola e processos de mediação específicos e distintos do escolar, observatórios astronômicos podem ser conceituados como espaços de divulgação e de educação não formal $[5,6]$. Os observatórios astronômicos possuem especificidades em suas práticas educativas e, desse modo, entendemos que nestes locais ocorre a transposição de conteúdos científicos destinados ao público visitante, sendo que tal processo envolve considerar não somente a seleção do que será divulgado, como também os elementos ligados ao contexto de divulgação e o perfil e as concepções do público [3, 7-9]. Assim, a partir de uma

de Física (EPEF), Simpósio Nacional de Educação em Astronomia (SNEA) e Simpósio Nacional de Ensino de Física (SNEF). 
experiência local em um observatório astronômico, este artigo pretende discutir elementos deste contexto para a formação de monitores em atividades de divulgação da Astronomia.

\section{A prática e a formação dos monitores em espaços não formais}

Grande parte dos observatórios astronômicos realiza atendimentos ao público a partir da mediação feita pelos monitores. Contudo, não há uma concordância na literatura quanto à adoção da expressão "monitor" e os significados a ela atribuídos, de modo que outras expressões são encontradas para designar indivíduos que, direta ou indiretamente, interagem com o público e ocupam funções nos espaços não formais em geral, tais como guia, mediador, facilitador, educador, animador, promotor, negociador, anfitrião, atendente, planetarista, entre outras $[2,4,10-13]$. No Brasil, a expressão monitoria tradicionalmente ocupou maior espaço no contexto educacional museal [13] e, por isso, mantemos essa terminologia em nossa investigação.

Responsável por representar a voz da instituição [14], o monitor ocupa papéis e funções diversas conforme as necessidades de cada local e do público, podendo ser desde funções relacionadas ao ensino e divulgação científica até mesmo ocupações técnicas de conservação e pequenos reparos do local. No âmbito nacional, essas funções são muitas vezes conduzidas de forma precária em locais que atravessam sérias dificuldades financeiras. Por isso, a função de monitor é vista como desafiadora já que lida com múltiplas tarefas e em contrapartida sofre com reveses que envolvem condições de trabalho e remuneração $[13,15]$. Este quadro se acentua na medida em que não há, de fato, a profissionalização dessa função em nosso país [13] e que, em muitos casos, são alunos de graduação (bacharelado e licenciaturas) e estagiários que atuam nos museus e centros de ciências e, especificamente, nos observatórios astronômicos, em alguns casos voluntariamente.

No aspecto das ações de divulgação voltadas ao público, há um consenso de que o papel do monitor se estende às funções que envolvem o diálogo entre os visitantes, o qual deve ser feito por meio de questões motivadoras e contextualizadas [16-18] em um percurso que faça da visita uma experiência agradável ao público. Posto às especificidades do local e o dinamismo inerente às atividades no espaço não formal, é imprescindível para a sua atuação a análise crítica e a reflexão por meio do levantamento de questões que levem ao aprimoramento da prática, fazendo deste um hábito cotidiano no processo educativo desses locais. Standerski (2007) [19] aponta algumas questões chaves que o monitor pode fazer durante seu percurso profissional:

Por que eu trabalho como monitor? Qual a minha função neste museu? Qual a função do lugar em que trabalho? Qual foi o meu percurso até aqui? (...) Por que eu escolhi essa atividade? Por que eu tomei essa decisão e não outra? Por que essa visita não foi boa? Por que essa visita foi boa? O que posso melhorar na próxima visita? Por que será que eles não responderam às minhas perguntas? $[9]$.

Essa análise, associada à sua formação, pode levar o monitor a elaborar estratégias e desenvolver saberes que enriqueçam sua experiência profissional.

\subsection{Os saberes dos monitores}

Investigando a atuação de duas monitoras em um museu de astronomia, Queiroz e colaboradores (2002) [1] buscaram estudar as dimensões relativas aos saberes da mediação. Para isso, fizeram a observação dessas monitoras durante visitas escolares realizadas no museu e, dentre os resultados das observações, identificaram saberes comuns à escola, isto é, aqueles saberes que em sua natureza são compartilhados com o ambiente escolar (conteúdos disciplinares, diálogo, transposição didática e linguagem). Foram identificados também outros saberes como sendo característicos dos museus (história local, interação com professores, conexões, história da humanidade, etc.), e compartilhados com a escola relacionados à educação em ciência (história da ciência, natureza da ciência, concepções alternativas). Os autores ressaltam que, com o levantamento de saberes, não se está propondo receitas para atividades realizadas nos museus e centros de ciências, mas sim fornecendo elementos diversos para a prática do monitor.

Em pesquisa realizada com monitores de um centro do Centro de Ciências de Araraquara - SP, Silva (2009) [2] procurou identificar o desenvolvimento, durante a formação, dos saberes necessários aos mediadores, e a inserção da prática reflexiva no desenvolvimento desses saberes. Além de estarem envolvidos em atividades com o público, os monitores que trabalham com alguns projetos específicos desenvolvidos dentro do Centro são também responsáveis pelo desenvolvimento de materiais didáticos para diversos níveis (apostila, simulações, etc.), atendimento a alunos que frequentam a biblioteca do Centro, realização de palestras, entre outras. É interessante destacar a existência de um rodízio mensal de monitores nas atividades desenvolvidas no Centro, de modo que cada monitor permanece em uma seção durante um mês. Ao final das atividades com o público, os monitores se reúnem com a supervisora com o objetivo de compartilhar as experiências advindas das visitas. Como parte da trajetória formativa e profissional, os monitores são estimulados a utilizar um caderno individual para anotações relacionadas às atividades que desenvolvem, com o intuito de "acompanhar o seu desenvolvimento profissional e refletir sobre as experiências vivenciadas" [2, p. 47]. 
Dentre os resultados, a pesquisadora identificou os seguintes papeis associados aos monitores daquele espaço $[2,20]$ : a) mediar o conhecimento; b) explicar os conceitos científicos envolvidos nas exposições, de maneira que a linguagem esteja adequada à idade dos visitantes; c) apresentar os espaços temáticos da instituição; d) receber e organizar os visitantes, de modo que se estabeleça uma relação profícua entre monitor e visitantes; e) zelar pelo espaço físico e integridade física e moral dos visitantes; f) complementar o ensino escolar dos visitantes escolhendo, para isso, atividades do espaço adequadas ao nível escolar e; g) difundir conhecimento científico. Sendo a monitoria uma atividade dinâmica, o monitor deve mobilizar diferentes papeis conforme as situações que se colocam diante dele.

Analisando a interação entre monitores e estudantes da XV Mostra de Física e Astronomia da Universidade Federal do Espírito Santo (UFES), Jeakel, Siman e Camiletti (2015) [21] procuraram encontrar comportamentos de um e de outro, esperados por ambos. Os autores partem da premissa de que, ao se preparar estudando para atuar em uma exposição, o monitor aprimora os seus próprios conhecimentos, sendo que o seu papel principal nas atividades da Mostra é ser mediador entre exposição/experimentos e o público visitante. O envolvimento de ambas as figuras na interação com os objetos em exposição é considerado favorável pelos pesquisadores para o desenvolvimento do conhecimento científico e da divulgação científica. Como resultado, percebeu-se que grande maioria dos alunos considerou fácil o entendimento das explicações dos monitores, notando-se também uma segurança desses para explicar os assuntos num intervalo de tempo considerado ideal pelos visitantes. Dentre as características desejadas pelos alunos nos monitores, destacamse: i) saber o que está sendo explicado; ii) ser engraçado; iii) deixar que o aluno pergunte à vontade e; iv) saber improvisar. Tais resultados apontam para uma reflexão efetuada pelos próprios autores na fundamentação teórica do trabalho, a respeito das expectativas do público ao visitar espaços de educação não-formal.

Mais do que o exercício de uma função, a montagem de aparelhos e exposições, ou mesmo a disposição de trabalhar com o público, a prática da monitoria pode angariar inúmeras experiências à formação profissional e pessoal do indivíduo, tais como mudanças de personalidade, aquisição de autoconfiança e experiência de lidar com diferentes faixas etárias [22]. Reconhecendo-se a sua importância para o desenvolvimento das atividades com o público, o monitor vivencia em sua experiência um processo de formação de longa ou curta duração. Não apenas como "treinamento" específico para a função, essa formação é bem mais ampla e pode permitir a aquisição de novos saberes [23] e contribuir para a identidade profissional do seu trabalho [12]. Nesse sentido, a formação de monitores é um aspecto relevante que, a nosso ver, deve ser analisado.

\subsection{A formação de monitores nos espaços não formais}

Reflexões e experiências presentes na literatura têm indicado parâmetros de formação de monitores diversificados, que dependem das demandas locais. Em pesquisa realizada com monitores licenciandos que atuam em exposições do CDCC2 ${ }^{2}$ Ovigli (2011) [24] buscou investigar a contribuição dos museus e centros de ciências para a formação destes enquanto futuros professores, bem como a possibilidade de inserção desses locais como espaços de estágios em disciplinas de Prática de Ensino na graduação. Para o autor, o monitor tem o papel de contribuir para o desenvolvimento dos objetivos educacionais da instituição em que atua ao concretizar a comunicação desta com o público visitante, propiciando "o diálogo com os visitantes acerca das temáticas em exposição, dando-lhes novos significados" [24, p. 137]. Uma vez que o monitor é também aluno da licenciatura, o autor considera a mediação um componente significativo à formação inicial do licenciando, com o objetivo de ampliar a visão sobre os estágios nos cursos de formação de professores.

Com o objetivo de analisar a formação dos monitores da Estação Ciência/USP ${ }^{3}$ com especial enfoque na mediação, Gomes (2008) [25] efetuou levantamento de informações relacionadas ao processo formativo desses profissionais naquele espaço. Em meados do ano de 2007, o programa de formação da Estação Ciência havia passado por uma reestruturação, na qual o monitor passou a ser visto como pesquisador e estimulador. No novo curso de introdução à monitoria, ministrado nesse período, agregavam-se os seguintes objetivos gerais à sua estrutura:

1) Orientar os alunos/estagiários nas atividades que serão desenvolvidas na monitoria da Estação Ciência; 2) Mostrar o trabalho desenvolvido na Estação Ciência como um todo: dimensão administrativa, museológica, educacional; 3) Discutir a especificidade do ensino não-formal em Museus de Ciência e sua importância para o ensino formal e para a formação do cidadão [25].

Por sua vez, os objetivos específicos vinculados à formação estruturada, estavam voltados para a prática do monitor no local, sendo esses:

1) Fornecer ao estagiário uma visão ampla do trabalho desenvolvido na Estação Ciência; 2) Reforçar princípios de solidariedade, companheirismo, cooperação, incentivar o diálogo entre estudantes de áreas diferentes a fim de exercitar a metodologia interdisciplinar [25].

Além da formação, os monitores eram estimulados a desenvolver atividades de pesquisa sobre as exposições do

\footnotetext{
2 Centro de Divulgação Científica e Cultural da USP - São Carlos. 3 Atualmente, a Estação Ciência encontra-se fechada para atendimentos.
} 
museu, participando de eventos e produzindo materiais didáticos e oficinas para professores e monitores. Do ponto de vista de Gomes (2008), essas iniciativas apoiam a concepção do monitor como um pesquisador atuante no museu. Como avaliação, os monitores são designados para atuar em determinadas exposições, sendo avaliados tanto a postura como o encadeamento das ideias apresentadas na exposição [25].

Marandino (2008) [14] identificou a presença de modelos diversos para a formação de monitores que, apesar de não serem excludentes, apresentam características distintas, sendo eles: 1) modelo centrado no conteúdo específico, que enfatiza conteúdos específicos considerados fundamentais para uma mediação bem-sucedida; 2) modelo centrado na prática, no qual a mediação é vista como processo formativo, ocorrendo em serviço; 3) modelo centrado na relação aprendiz e mestre, em que monitores veteranos considerados experientes na mediação realizam atividades com monitores aprendizes que observam; 4) modelo centrado na auto formação, no qual o monitor é responsável pelo seu próprio processo formativo através de leituras e reflexões e; 5) modelo centrado na educação e comunicação, que enfatiza aspectos da educação e comunicação em museus. Percebe-se, muitas vezes nas instituições museais, a ênfase dada aos conteúdos conceituais na formação de monitores, deixando os aspectos educacionais e comunicacionais a cargo da observação da prática de outros monitores.

Em pesquisa realizada com monitores da Casa da Ciência/UFR. [4, Brito (2008) [15] enfatiza alguns aspectos considerados relevantes para a formação dos mediadores desse espaço. No processo de seleção, são feitas entrevistas, dinâmicas de grupo e formação técnica - oferecida por profissionais da área, professores e pesquisadores -, sendo que esta última consiste em aspectos teóricos da divulgação científica, educação, comunicação, autoconhecimento e temática das exposições presentes no espaço. A autora enfatiza também alguns saberes que o mediador deve ter domínio para o desenvolvimento efetivo das atividades no espaço.

O mediador precisa ser capaz de trabalhar em equipe, estar aberto para o aprendizado múltiplo, ter clareza de suas limitações no que diz respeito às informações científicas e desenvolver a capacidade da comunicação com públicos plurais, entendendo a necessidade de adaptação de linguagem a partir das perspectivas e dos interesses daquele público [15].

Ambos os contextos dos saberes e da formação do monitor são importantes para analisarmos experiências de mediação em espaços não formais e, por isso, as reflexões aqui expostas apoiaram e fundamentaram o estudo da formação dos monitores em nosso local de estudo.

\footnotetext{
$\overline{4 \text { http://www.casadaciencia.ufrj.br/. }}$
}

\section{Metodologia}

Para investigar a prática dos monitores a partir da visão que eles possuem sobre ela, adotamos uma metodologia qualitativa de pesquisa, cujas principais dimensões envolvem: a) apropriabilidade de métodos e teorias (o objeto de estudo, em sua totalidade, determina a escolha do método); b) perspectivas dos participantes e sua diversidade; c) reflexividade do pesquisador e da pesquisa (subjetividade do pesquisador - impressões, irritações, sentimentos, etc. - intrínseca ao próprio processo de pesquisa); d) variedade de abordagens e de métodos na pesquisa qualitativa [26]. Deste modo, a investigação buscou entender, na perspectiva dos sujeitos e a partir da coleta de dados por diferentes métodos, a prática dos monitores e a formação local vivenciada por eles.

Como instrumentos para a constituição dos dados, utilizamos questionários, entrevistas e observações das atividades dos monitores. Os instrumentos foram construídos com o objetivo de identificar, as motivações entre os participantes para a monitoria, a atuação deles no local, as dificuldades encontradas na formação e na atuação em campo, e as concepções por eles sustentadas sobre determinados assuntos.

Optamos pela escolha de três instrumentos com o objetivo de efetuar uma triangulação dos dados coletados nestes, a fim de superar limitações individuais e dar igual relevância aos instrumentos escolhidos [26, 27]. Após a elaboração do questionário e roteiro de entrevista, partimos para validação desses instrumentos através de análise crítica por pesquisadores da área de educação em ciências e divulgação científica. Esse processo em que o instrumento de coleta de dados é avaliado por pareceristas é conhecido com validação de conteúdo. De acordo com Vianna (1976) [28], a validade de conteúdo não é determinada estatisticamente, mas sim resulta do julgamento de diferentes examinadores, que analisam a representatividade dos itens em relação às áreas de conteúdo e à relevância dos objetivos a medir.

Após a validação, foi produzida versão final do questionário e roteiro de entrevista. O questionário foi aplicado online mediante anuência de 14 monitores, participantes da pesquisa, a partir de ciência do Termo de Consentimento Livre e Esclarecido (TCLE), aprovado pelo Comitê de Ética via Plataforma Brasi 5 A partir de leitura dos dados obtidos nos questionários, selecionamos 4 dos monitores participantes da etapa anterior para realização das entrevistas. A seleção se deu conforme o volume e a pertinência das informações fornecidas nos questionários. Além disso, levamos em consideração o tempo de permanência de cada monitor, de modo que, dos quatro monitores entrevistados, dois atuam há mais de dois anos no Observatório, um atua há pouco mais de um ano e o outro atua há menos de um ano no local.

A análise dos dados desta pesquisa está fundamentada na Análise de Conteúdo [29, 30], cujo ponto de partida é

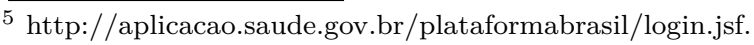


a mensagem em sua forma verbal oral, escrita, silenciosa, figurativa, documental ou diretamente provocada [29]. Parametrizados pelas discussões e subsídios apontados pela literatura e tomando por base o objetivo do trabalho, qual seja, caracterizar a prática dos monitores, buscamos identificar as motivações que levaram os monitores a ingressar no ambiente não-formal, a atuação destes nas atividades desenvolvidas no mesmo espaço, as dificuldades encontradas tanto nas atividades em campo quanto na formação, o processo formativo vivenciado por eles, as concepções existentes sobre diversos assuntos, dentre outros elementos teóricos e práticos. Seguindo os procedimentos indicados por Bardin (2009) [30], fizemos uma leitura flutuante dos dados coletados nos três instrumentos, permitindo-nos elencar hipóteses preliminares responsáveis por guiar nossa análise. Para codificação das unidades de registro (UR), procedemos com o recorte destas em cada um dos três instrumentos, e, por conseguinte, o agrupamento das UR de acordo com o significado de cada uma delas (agrupamento conforme nível semântico). Em seguida, feita uma codificação e categorização preliminares, passamos à triangulação dos dados categorizados dos três instrumentos para, em seguida, proceder à elaboração dos índices finais e indicadores (frequência) $)^{6}$. Finalmente, cumpridas essas etapas, foram estabelecidas as categorias e subcategorias definitivas do trabalho, sobre as quais debruçamos nossa análise.

\footnotetext{
${ }^{6}$ Maiores informações sobre os recortes de Unidades de Registro (UR) efetuadas nos dados da pesquisa estão disponíveis no Apêndice G, em Barros (2017).
}

Os dados desta pesquisa foram coletados no Observatório Didático de Astronomia "Lionel José Andriatto", vinculado à UNESP/Bauru, espaço destinado à divulgação da astronomia entre escolas e público em geral na região de Bauru - SP. Desde 2004, o Observatório realiza projetos de divulgação que envolvem a realização de oficinas, atividades infantis, exposições, sessões de palestras, sessões de observação do céu, cursos de extensão, entre outras [6]. Grande maioria dessas atividades é realizada no âmbito dos atendimentos escolares (semanais) e atendimentos ao público (mensais), recebendo uma média de público anual total de 3000 visitantes.

Sediado em um prédio de dois andares 7 que contém diversas salas e uma cúpula no terraço, o Observatório recebe o público em visitas que duram em média uma hora e meia. A equipe é formada por monitores majoritariamente voluntários, oriundos de diversos cursos e formação. No ano de 2015, havia 19 monitores ativos na equipe (entre alunos e professores), vinculados a cursos de graduação e pós-graduação da UNESP.

\section{Resultados}

Tomando por base a análise de conteúdo e com a finalidade de investigar a prática dos monitores do Observatório Didático de Astronomia da UNESP, organizamos os dados analisados em três grandes temas, os quais comportam categorias e, em alguns casos, subcategorias, representados na Figura 1, sendo esses temas: 1) perfil do monitor e seus diferentes papeis; 2) tendências forma-

7 Atualmente, o prédio encontra-se fechado para manutenção.

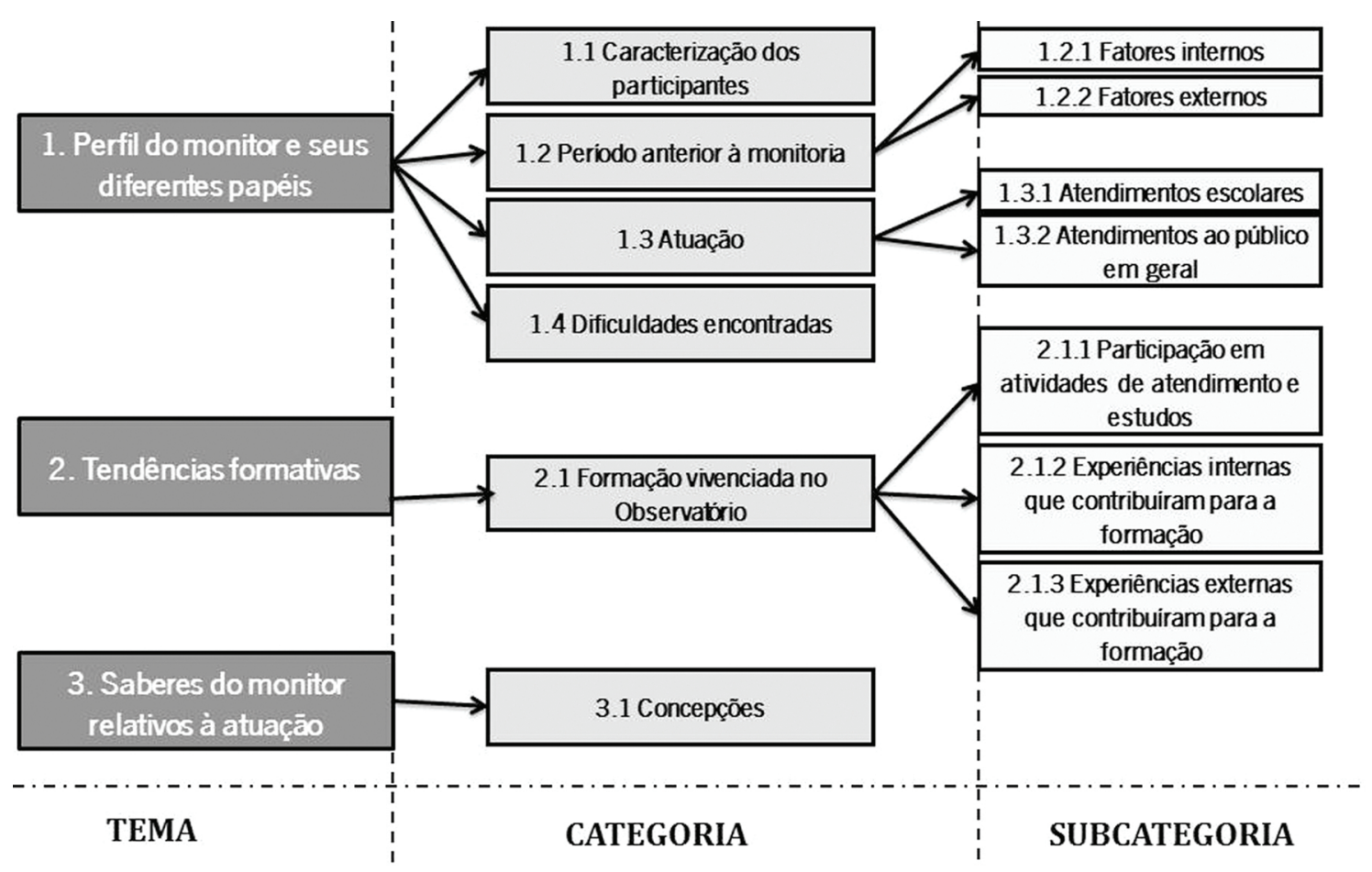

Figura 1: Organização dos temas e categorias da pesquisa. Fonte: elaborado pelos autores 
tivas e; 3) saberes do monitor relativos à sua atuação. Os depoimentos dos monitores que constam nesta seção, foram extraídos a partir dos questionários respondidos por eles e transcrições de áudio das entrevistas realizadas. Para preservação da identidade dos sujeitos, enumeramos os monitores com a sigla M, seguida de numeração. Nos depoimentos em que constem nomes de pessoas citadas pelos entrevistados, utilizamos nomes fictícios seguindo essa mesma finalidade.

\subsection{Perfil do monitor e seus diferentes papéis}

$\mathrm{Na}$ caracterização dos participantes, mais da metade dos monitores cursa licenciatura em física na UNESP/Bauru - integrada ao bacharelado ou distinta deste - e está há pouco tempo no Observatório. Este perfil reforça aquele encontrado em grande parte dos espaços não formais, pois os monitores de museus de ciências são em geral graduandos de cursos de áreas afins a esses espaços. Uma rápida consulta à estrutura curricular do curso de Física da UNESP, disponível na internet 8 , nos chama a atenção para a ausência de disciplinas diretamente relacionadas à educação não-formal ou divulgação científica, seja como obrigatórias ou optativas, na estrutura curricular do curso de licenciatura em física frequentado pelos aluno ${ }^{9}$ Tal fato, não é exclusivo da realidade local ou nacional [31], e estudos vêm mostrando que ainda são poucos os cursos de formação inicial de professores em nosso país que abordam essas temáticas na forma de disciplinas [32]. Contudo, esse fato não impede a abordagem de tópicos da divulgação científica e de educação não formal em disciplinas da área de ensino como nas metodologias de ensino e nos estágios, este último especialmente indicado por autores como oportunidade para enriquecer a formação do licenciando a partir de práticas em espaços de educação não formal [6, 24, 32].

No período anterior à monitoria, procuramos esboçar aspectos da experiência anterior à entrada do monitor no Observatório, relacionados com a prática deles no local. Nesta categoria enquanto fatores internos (isto é, relacionados ao Observatório), notam-se as experiências de participação em programas desenvolvidos pelo próprio Observatório ou realizadas por este em algum local (ex.: feiras de ciências e eventos regionais), fazendo dessas atividades uma oportunidade de interagir com os visitantes e até mesmo instigá-los à monitoria, como expresso na fala de M4:

8 Disponível em: http://www.fc.unesp.br/\#!/departamentos/ fisica/cursos/fsica/grade-curricular/, acesso em: 13 fev. 2018.

9 É válido mencionar a recente atualização curricular do curso de Licenciatura em Física da UNESP-Bauru, que permitiu a inserção, como disciplina obrigatória do $4^{\circ}$ Termo, do componente curricular "Astronomia: Terra e Universo", a partir de 2016. Consta, no plano de ensino da referida disciplina, a realização de atividades nãoformais e informais para o ensino de Astronomia (disponível em: https://goo.gl/KHtHm9 acesso em: 13 Fev. 2018).
Tive o primeiro contato [com o Observatório] em 2013, quando o Eduardo, ele fez um curso de extensão, né, com os alunos de... Os alunos de licenciatura. Era um curso de.... De prática de ensino de física, né? Daí, todo ano ele fazia um curso diferente, daí no ano de 2014 teve outro curso, 2015 teve o... 2015 teve a... O curso com o Fernando, né, que eu participei. Daí, até então, eu não pensava em ficar em Bauru pra fazer graduação, né, pensava em ir pra São Paulo. (...) Só que daí eu vi que aqui tinha um ambiente onde eu poderia tá [sic] estudando Astronomia, tá [sic] participando de um grupo de estudos, tá [sic] participando de um observatório, daí foi assim que eu resolvi ficar em Bauru, pra fazer física aqui, e depois que eu entrei na graduação eu já procurei o... A equipe. (M4).

Quanto aos fatores externos ao Observatório,isto é, experiências externas potencialmente motivadoras à monitoria, alguns monitores destacaram a visitação a outros espaços de divulgação científica (museus, centros de ciências, parques científicos e planetários), além do desenvolvimento de atividades de astronomia na escola local em que estudavam.

Eu comecei a estudar astronomia para a $\mathrm{OBA}$ na Quinta Série, uma professora minha dava aula de astronomia, e eu comecei com a OBA e depois no colegial eu prestei só um...Uma, não lem...acho que prestei até o terceiro. Depois eu fiz parte de um show de Astronomia que essa mesma professora organizou, e depois eu fiz um grupo de Astronomia amadora aqui na minha cidade (M5).

Sempre visitei museus e centros de ciência devido meu pai ter um grande [sic] curiosidade em temas variados da ciência. Já tinha visitado o Planetário de Brotas e o Observatório de Piracicaba em atividades rotineiras dos mesmos (M13).

Ao serem indagados sobre a motivação pessoal para se tornar monitor, prevaleceram justificativas afetivas/emocionais em relação à astronomia, como destacados nas citações abaixo.

O que me levou a ser monitor do Observatório foi o grande interesse e amor pela astronomia (M4).

Sempre me interessei por astronomia, dessa forma não pensei duas vezes quando descobri que poderia ser voluntário no observatório (M9).

10 Olimpíada Brasileira de Astronomia e Astronáutica. 
Sempre fui apaixonada por astronomia e vi isso como uma oportunidade de aprender mais sobre o assunto e ainda ter contato com o que gosto (M11).

Na atuação, através da tomada de notas de campo obtidas pelas observações, buscamos investigar os elementos relativos às ações dos monitores em dois momentos distintos. Dadas as diferenças de contexto (públicos com perfis diferentes), espera-se que sejam dados enfoques distintos à monitoria. Assim, neste quesito, procuramos saber dos monitores quais as principais estratégias elaboradas por eles para melhoria da prática e superação de eventuais dificuldades nas seguintes situações:

1) atendimentos escolare $\$ 11$ normalmente, os monitores fazem a montagem dos instrumentos astronômicos (telescópios e objetos para exposição), e conversam com os visitantes numa sala específica do Observatório. $\mathrm{Na}$ fase de preparação desse atendimento, é comum a troca de informações entre membros da equipe com o intuito de orientar os responsáveis pelo atendimento sobre como lidar com o público e o tempo de duração da visita. Já na recepção, os monitores dão boas vindas aos visitantes e apresentam o Observatório contando uma rápida história deste e os recursos presentes no local. São feitas algumas perguntas e questionamentos para despertar a atenção do público. Durante as atividades, os monitores procuram levantar perguntas com o intuito de estimular o público visitante a participar das mesmas. Para isso, são utilizados exemplos e conceitos estimulando as respostas dos visitantes. Um dos participantes da pesquisa destaca a diferença entre os tipos de atendimento e o que se deve fazer para atuar nesses diferentes contextos, enquanto que outro monitor exemplifica essa diferença ao explicar seu modo de atuar conforme os visitantes que atende.

Num aberto ao público, você tem que fazer uma coisa mais geral, porque você... Ali você vai ter criança, cê [sic] vai ter universitário, cê [sic] vai ter idosos... Agora quando você vai atender a escola, você sabe a faixa etária que vai tá [sic] ali. (M4).

Procuro atender a demanda, trazer assuntos de interesse do público (M10).

Outro monitor destaca ainda que, tendo em vista o fato de o público escolar trazer diversas perguntas, é necessário que ele saiba lidar com isso. Assim, segundo ele, para atuar com o público, o monitor deve conhecer:

O básico de Astronomia, pois o público sempre terá muitas perguntas, e também é necessário a facilidade de conversar com eles e entender o que pensam (M8).

\footnotetext{
11 São atendimentos realizados com alunos de instituições de ensino básico ou superior (escolas, faculdades, institutos, etc.).
}

No contexto da atuação do monitor, as formas de mediação e o próprio discurso do mediador ganham destaque e devem ser problematizadas. Caffagni e Marandino (2012) [33], estudaram alguns dos fatores que influenciam a mediação e indicaram que a formação pessoal, a formação oferecida pela instituição, as maneiras com que ele estrutura a forma e o conteúdo de sua fala, por meio de questões-chave (muitas vezes apenas retóricas) e de analogias e metáforas, e as especificidades do espaço museal são elementos cruciais na produção do discurso do monitor.

Verificou-se nesse contexto de atendimento o uso de perguntas para motivar a participação dos visitantes, detectando-se entre os discursos dos monitores: a) perguntas relacionadas a conteúdos conceituais; b) perguntas "retóricas" e; c) perguntas que direcionam para a resposta. As perguntas relacionadas a conteúdos conceituais são aquelas que os monitores fazem para articular ou revisar algum dado ou conceito do público, como por exemplo, a distância entre a Terra e a Lua, a quantidade de dias de um ano, o conceito de marés e de estações, etc. Já as perguntas ditas "retóricas" são aquelas que o monitor geralmente faz ao final da sua apresentação para dar prosseguimento às etapas seguintes, como por exemplo, perguntas como "entenderam?", "deu pra entender?", "vocês têm dúvida?", "todo mundo entendeu?", etc. Enquanto que as perguntas que direcionam para a resposta são aquelas cujo enunciado contém indícios que levam o respondente a fornecer a resposta da pergunta, sem necessariamente sabê-la previamente. Como exemplo, em um dos atendimentos observados, uma monitora fez a seguinte pergunta aos visitantes: "será que a Lua só tem quatro fases?" (grifo nosso). Neste caso, o uso do advérbio (só) tende a modificar substancialmente a compreensão do ouvinte sobre a pergunta, levando-o a afirmar, quase que automaticamente, que não existem apenas quatro fases da Lua (embora seja possível que o visitante desconheça previamente essa informação).

2) Atendimento ao público em geral: nesse tipo de atendimento, realiza-se basicamente observação do céu com telescópio, palestras curtas de 15 minutos, exposições e sessões de vídeos curtos. O planejamento do atendimento é realizado conforme um tema a ser definido em reunião de equipe e está geralmente vinculado a eventos astronômicos do período ou temas correntes da Astronomia. Na fase de preparação, alguns monitores afirmaram recorrer à leitura de materiais de referência (ex: vídeos, artigos, livros, entre outros). No planejamento, discutemse as atividades que serão realizadas, a disponibilidade de monitores para a ocasião e o revezamento necessário entre membros da equipe. De posse das notas de campo obtidas a partir de observações in loco das atividades, notou-se, por exemplo, o uso de estratégias de alguns monitores em palestras. Tais estratégias são aquelas em que o monitor usa diferentes entonações para chamar a atenção do público, além de contar histórias e exemplos e fazer perguntas sobre assuntos que chamem a atenção 
dos visitantes, utilizando o bom humor para criar uma atmosfera de descontração. Nessa experiência, alguns monitores relataram como foi lidar com o público pela primeira vez.

Eu estava como auxiliar apenas, mas, foi bem interessante ver a reação das pessoas quando suas dúvidas eram tiradas. Não me senti 100\% preparada, mas, consegui lidar muito bem com a situação pois as dúvidas do público [sic] eram simples de serem tiradas (M11).

Foi uma experiência muito interessante, já havia trabalhado com público antes mas, era sempre muito específico. No observatório lidamos com diversas faixas etárias e as mais diversas concepções (M1).

Outros monitores também relataram a experiência de interagir com o público observando a receptividade deste frente aos discursos do monitor, e explicaram como fazem para lidar com visitantes de perfis tão distintos.

Tento adequar a linguagem de acordo com faixa etária e formação dos participantes (M12).

Ser paciente e respeitar o tempo de aprendizado de cada um, usar termos usuais as vezes ajuda mas em certos casos não podem ser usados pois podem retirar o sentido do contexto apresentado (M14).

M14 chama a atenção para o uso de "termos usuais",o que inferimos como sendo expressões de conhecimento e uso comum em geral a fim de se aproximar do público para comunicação de conceitos científicos, sem, contudo, exacerbar o seu uso sob o risco de comprometer o conteúdo que está sendo explicado.

Ao buscar estratégias para melhoria da prática, muitos monitores afirmaram recorrer a outras fontes para complementação da formação, principalmente o estudo de conceitos de Astronomia. Para alguns monitores, bastariam mais conhecimento e leitura individual para aprimoramento da sua prática e superação de dificuldades, enquanto que outros reportaram conhecimentos que seriam necessários para saber comunicar com os visitantes, superando o receio e o medo de conversar, e desenvolvendo a habilidade de comunicação em diferentes enfoques.

Eu sempre penso que tem que melhorar alguma coisa, porque às vezes tem algumas perguntas, tem algumas coisas que, ah, eu não consigo responder com total clareza, é... Às vezes eu nem respondo, né, não dá mesmo, mas, é nessa questão mesmo. Algumas informações técnicas sobre o Observatório, sobre os telescópios. (M4).

Falta eu aprender realmente a falar em público sem medo, e conseguir me expressar de maneira que todos compreendam (M11).
No âmbito das dificuldades encontradas, foram constatadas três grandes dificuldades mapeadas pela pesquisa:

1) Problemas de interação com o público durante as atividades: tais problemas consistem em descompassos entre o que é preparado pelos monitores e as expectativas dos visitantes ao chegar ao local; dificuldades de suscitar a atenção do público durante as atividades; pouca abertura à manifestação dos visitantes em determinadas seções, e; inexperiência do monitor em lidar com diferentes tipos de público.

Por exemplo, o EJA, eu nunca trabalhei com EJA. Então, tipo, como é que eu, tipo, acho que eu sei me preparar pra escola, mas, precisava de mais respaldo nesse sentido, tipo, como se preparar pro... Pra um dos públicos específico [sic]. (M2).

Outra dificuldade relatada pelos monitores se deu com assuntos repercutidos na mídia, muitas vezes de maneira sensacionalista, que o público indaga esperando deles confirmação e aceitação dessas informações, ao invés de questionamentos.

2) Erros conceituais na comunicação com o público e uso de explicações complexas e técnicas: em alguns momentos durante explicações dadas pelos monitores, notou-se a presença de erros conceituais em que conceitos físicos eram confundidos, explicações conflitantes eram apresentadas de forma consensual e erros de português eram cometidos, além de concepções de senso comum presentes em alguns discursos dos monitores. As explicações complexas e técnicas são aquelas em que o monitor utiliza conceitos extremamente complexos para o público em que se está trabalhando, desconsiderando-se uma transposição didática necessária para tal. Percebeuse também o uso problemático de conceitos feito por alguns monitores durante as atividades, caracterizado pela menção a exemplos históricos controverso: ${ }^{12}$ e realismo ingênuo em determinadas explicações. $\mathrm{O}$ uso de analogias também se mostrou problemático tanto pelas limitações da analogia, não devidamente consideradas pelos monitores, quanto pela dificuldade em se explorar a própria analogia nas suas explicações.

3) Problemas no planejamento e organização das atividades: ocorrem quando os monitores não são bem instruídos para as atividades que realizarão, relatando-se problemas de desorganização e falta de planejamento.

(...) quando iniciei não me explicaram quais as atividades desenvolvidas, nem ao menos o funcionamento dos materiais ali presentes,

\footnotetext{
12 Exemplos históricos controversos são episódios históricos frequentemente citados, mas que possuem validade histórica contestada por pesquisadores, sendo até mesmo em alguns casos considerados como mitos históricos, tais como a queda da maçã observada por Newton, a experiência de Arquimedes com a coroa do rei Hierão, entre outros.
} 
não sabia ao certo como lidar com público e tive que aprender sozinha (M7).

As dificuldades até aqui discutidas sugerem maior atenção à necessidade de um planejamento estruturado das atividades, nas quais cada monitor seja responsável por cada função, preparando-se para ela antecipadamente com o suporte fornecido pelo processo formativo local. Além dos conteúdos específicos (conhecimentos de Astronomia), a formação deve focar também na comunicação feita entre o monitor e o público, com o objetivo de superar falhas e dificuldades. Essa dimensão da formação requer do monitor o desenvolvimento de diversos saberes que o leve a superar dificuldades de interação, "quebrando o gelo" da visita, estimulando os visitantes a participar das atividades tocando, manipulando os objetos e instrumentos, mencionando fatos, curiosidades e histórias que, de alguma forma, estejam relacionadas à exposição ou que chamem a atenção deles para um tema específico da exposição, estimule-os a narrar suas experiências pessoais, utilizar exemplos do cotidiano para contextualização, etc.

\subsection{Tendências formativas}

$\mathrm{Na}$ formação vivenciada no Observatório, procuramos investigar os principais mecanismos considerados para a formação local. Durante a participação em atividades de atendimento e estudos, constatou-se com relativa frequência o acompanhamento de monitores com maior experiência (veteranos) por parte dos novatos, com a função de auxiliar e observar a prática dos primeiros entre o público nos atendimentos do Observatório.

Quando a gente entra lá, no...normalmente a gente fica só observando, acompanhando os monitores que já estão lá, acompanhando as visitas de escola e a visita de aberto ao público. $\mathrm{Na}$ época só tinha essas atividades e tinha a oficina de lunetas, que era o que a gente fazia também, preparava materiais e a gente montava o curso de lunetas, quem dava era os veteranos, pessoal que tava [sic] no mestrado lá, e a gente acompanhava essa oficina (M2).

Outro espaço paralelo à formação com veteranos que se mostrou relevante na formação foi o grupo de estudos do Observatório, no qual se discutiram diversos temas relacionados à astronomia ou divulgação científica, sendo geralmente conduzidos pelos responsáveis pela administração e coordenação do Observatório.

Inicialmente a gente fazia o acompanhamento com os monitores veteranos e a gente tinha grupo de estudo. É...foi feito no meu primeiro ano, não me lembro se 2 ou 3 grupos de estudo. Só que eu estudava bastante à parte e conversava com o pessoal. Então, tudo que eu tinha dúvida eu traz...tipo, eu chegava no grupo de estudo já com dúvidas, e tinha muita gente que chegava para receber o conteúdo ainda, né? (M13).

Nas experiências internas que contribuíram para a formaçã $\tilde{~}^{13}$ muitos monitores enfatizaram a interação com o público visitante como sendo de grande relevância, visto que nesse contexto o monitor troca conhecimentos e desenvolve habilidades que permitem superar dificuldades e fazer com que ele tenha posturas adequadas na visita.

Todos os dias eu aprendo algo novo, e aprendi a lidar melhor com pessoas, o que era um grande problema pra mim (M11).

O primeiro grupo que recebi foram crianças do grupo de escoteiros, eu no começo estava insegura, mas as crianças estavam tão empolgadas que eu notei que seria um bate-papo sobre astronomia, com pessoas que também eram apaixonadas por aquilo de certa forma, aí eu me soltei, notei que estávamos todos ali pra aprender (M2).

De acordo com M2, a insegurança cessou com sua aproximação do público, quando percebeu que poderia ter uma conversa agradável com os visitantes. Essa insegurança decorre normalmente da ansiedade em o monitor apresentar muitos conteúdos científicos ao público. A preocupação com explicações cientificamente corretas, com expectativas do público frente às suas explicações e provavelmente a busca pela satisfação pessoal com a própria prática, podem gerar desconforto no momento em que ele lida com os visitantes.

A monitoria também proporciona o aprendizado de conceitos científicos [2], uma vez que o monitor deverá conhecê-los previamente para assumir as atividades de atendimento, fator este que acreditamos ter sido importante para motivar alguns monitores a optar pela atuação. A confiança e a satisfação também foram consideradas pelos participantes da pesquisa como adquiridas nessas experiências, algo que acreditamos estar analogamente relacionado à situação vivenciada por M2, na fala acima. Finalmente, o trabalho em equipe foi visto pelos monitores como uma experiência válida, dado que as atividades exigem deles habilidades de coordenação, planejamento, divisão de tarefas e engajamento nas ações locais. Por último, é interessante destacar a iniciação à pesquisa acadêmica como uma experiência resultante da própria monitoria e considerada importante entre alguns dos participantes.

Nas experiências externas que contribuíram para a formação, alguns monitores mencionaram buscar cursos de extensão universitária (presenciais ou à distância) como alternativa para a formação, buscando novos conhecimentos. É interessante notar que os cursos de extensão

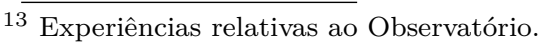


procurados pelos monitores são, sobretudo, de conteúdos de Astronomia. Não encontramos nesses relatos informações sobre a participação em cursos sobre comunicação científica, educação em museus, museologia, ensino de Astronomia, etc.

[...] Eu fiz curso de férias, curso à distância do Observatório Nacional, sempre procurando é... Fazer os cursos pra tá [sic] sempre me atualizando (M2).

Curso do Observatório Nacional de Cosmologia, revistas e artigos científicos acesso a sites da área, como Nasa, Observatórios e cursos Coursera (M12).

Curso de introdução à Astronomia do IAGUSP (M14).

Outros projetos também contribuíram para a experiência da monitoria, como é o caso do PIBID ${ }^{14}$ em que o monitor desenvolve atividades de ensino de apoio ao professor, devendo para isso estudar e produzir materiais.

\subsection{Saberes do monitor relativos à atuação}

Em se tratando das concepções, procuramos saber dos participantes, o que eles entendem como sendo saberes relevantes para a função de monitor e o que se deve considerar em propostas de formação. Para a grande maioria dos participantes, é fundamental saber os conceitos básicos de astronomia e buscá-los em fontes como materiais didáticos e disciplinas de astronomia. Porém, esse conhecimento deve estar relacionado com um segundo saber, o de se comunicar com o público visitante, desenvolvendo recursos e estratégias capazes de divulgar o conhecimento astronômico. Neste sentido, alguns monitores mencionaram a necessidade da oratória e de se expressar compreensivelmente entre os visitantes.

Primeiramente, o monitor deve ter um conhecimento confiável sobre Astronomia. Em segundo lugar, ele deve entender sobre pedagogia e ensino de Astronomia. (M4).

[é necessário] o conteúdo a ser apresentado, qual publico [sic] ele está lidando, como transpor esse conhecimento, como fazer dessa visita uma visita marcante para o visitante (M14).

Os monitores mencionam ainda a importância de saber explicar determinados conceitos, conforme o público visitante. Os saberes mobilizados nesse processo são conceituados por Queiroz e colaboradores (2002) [1] como saberes compartilhados com a escola, isto é, conhecimentos que têm em comum o fato de serem pertinentes

14 Programa Institucional de Bolsas de Iniciação à Docência (CAPES/MEC). à prática do professor no ambiente escolar.Resultados semelhantes foram encontrados por Silva (2009), entre monitores de um centro de ciências. Uma vez percebido que os saberes compartilhados com a escola se sobressaem em relação a outros saberes (como os do museu), a autora justifica essa tendência a partir das concepções sustentadas pelos monitores sobre o espaço museal.

(...) Os monitores possuem uma concepção de que os espaços de educação não-formal, como os centros de ciências, apresentam aproximações com os espaços formais de educação como a escola [2].

Alguns monitores mencionaram também a necessidade de se saber outro tipo de conhecimento, relativo ao local de trabalho do monitor e que envolve tanto a infraestrutura local como a dinâmica inerente às atividades desenvolvidas. Alguns dos participantes consideram esse saber tão importante quanto o do conteúdo e da comunicação.

[é importante] A pessoa conhecer sobre o assunto e conhecer o lugar que está, porque é diferente da gente, tipo, quando você vai ensinar alguém você precisa saber sobre, isso é óbvio. Mas, é diferente a maneira que você, por exemplo, ah, eu sou professor, eu sei dar aula e eu vou saber trabalhar no Observatório. Não! Eu penso isso, né, eu acredito que a forma de se trabalhar, né, deveria ser, ser dif...abordada, porque é diferente, né, a gente trabalha com várias faixas etárias, é...é uma coisa muito dinâmica, muito aberta, não é aquela coisa fixa, então acho que, além de você ter um grande conhecimento não só dos conteúdos mas sim do que tá [sic] passando na mídia sobre isso, porque pra você desconstruir alguma coisa eu acredito que você tem que saber aquela coisa. (M13).

M13 deixa claro que há uma diferença entre a atuação do professor e do monitor, visto que os espaços são diferentes e exigem práticas distintas. Especialmente no caso de um observatório, com um público bastante heterogêneq ${ }^{15}$ o monitor deve estar sintonizado com o que há de mais atual na astronomia, haja vista a velocidade com que as informações se propagam nas diferentes mídias e são popularizadas. Assim, segundo esse monitor, o grande diferencial envolvido no Observatório é a diversidade de públicos que terá de lidar, diferentemente do professor que está habituado a atuar para uma série específica na escola.

M4 esclarece que o conhecimento de astronomia do monitor deve ser confiável, o que pode ser entendido como uma segurança necessária em determinado conteúdo na

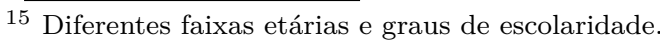


hora de se apresentar ao público. Jeakel, Siman e Camiletti (2015) [21] reconhecem essa importância para a interação com os visitantes que assistem a uma demonstração de experimento.

É importante ressaltar que a segurança do monitor na hora da explicação do experimento contribui para fomentar a ocorrência de tipos qualitativamente diferenciados de motivação do aluno (MACHADO e RUFINI, 2012) Sendo assim, é possível que a forma com que o monitor apresenta determinado experimento, possua ligação direta com a atenção e o interesse prestado pelo aluno à suas explicações $[21]$.

Outro monitor ressalta a importância do saber trabalhar em grupo. Para ele, isso significaria fazer com que o monitor refletisse sobre a sua prática entre equipe, buscando sempre o consenso dos colegas para prosseguimento às atividades do local.

Acredito que um monitor deve primariamente, saber trabalhar em grupo, deixando de lado egoísmos e pensando no todo, seja nas visitas escolares ou nos eventos de aberto ao público. Um monitor também deve estar ciente de sua própria ignorância, devê [sic] reconhecer que se não tem conhecimento de um assunto não deve discutir sobre o mesmo utilizando-se de informações duvidosas (M9).

A motivação pessoal também é considerada um saber necessário para alguns monitores. Neste caso, os participantes mencionaram atitudes como o "desejo de aprender", "força de vontade", "levar o trabalho a sério", etc., como atitudes de um saber de natureza afetiva. Ao identificar resultados similares entre os monitores do $\mathrm{CCA}{ }^{17}$ sem deixar de reconhecer a relevância desses saberes para a prática, Silva (2009) [2] afirma que:

Essa ênfase nas características gerais pode sugerir que os monitores ainda não têm condições de discernir dentre as habilidades e saberes profissionais, quais se enquadram na função de um monitor ou ainda, a noção de que possuir apenas tais qualidades e aspectos afetivos é suficiente para que se adquira ou desenvolva as habilidades e saberes necessários a um monitor [2].

\section{Discussão}

De acordo com os dados obtidos pela pesquisa, a experiência como monitor é enriquecida à medida em que se

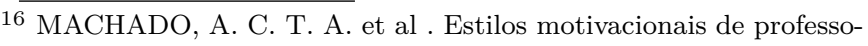
res: preferência por controle ou por autonomia. Psicol. cienc. prof., Brasília, v. 32, n. 1, p. 188-201, 2012.

17 Centro de Ciências de Araraquara - SP (http://www.cca.iq unesp.br/). variam os contextos de atendimento. No entanto, devese atentar para algumas dificuldades identificadas nesse contexto, especialmente quanto ao planejamento dos atendimentos escolares e problemas de comunicação.

Dentre as motivações pessoais para a monitoria, notouse frequentemente uma dimensão afetiva nas respostas dadas pelos participantes. Essa dimensão pode representar a curiosidade pela astronomia e a satisfação do monitor em atividades que ele participou na condição de visitante de espaços não formais, ou participante de cursos e programações da área, ou mesmo pelo incentivo recebido em seu contexto pessoal. Nota-se, também, um aspecto motivador intrínseco às atividades de divulgação científica para com o público, já que o contexto da visita ao museu pode ser poderoso e estimulante, apontando para a relevância de uma reflexão relativa à atuação dos seus monitores, associada diretamente ao papel deles como educadores e comunicadores [34]. Neste sentido, percebe-se que a atuação do monitor possui uma dimensão motivadora quando este exerce a mediação de exposições e de observações com telescópios e outros instrumentos astronômicos, a exibição de softwares interativos, entre outras ações. É seu papel criar condições para manifestação do público e, para isso, não nos parece suficiente conhecer os conceitos físicos e/ou astronômicos relacionados às atividades, mas sim outros saberes $[1,2]$, necessários a uma monitoria bem sucedida. Não podemos deixar de citar ainda a importância do perfil pessoal do monitor que em determinados momentos utiliza o bom humor, gestos e falas que tornam a visita descontraída, estimulante e agradável.

Por outro lado, algumas das dificuldades encontradas em campo pelos monitores se contrapõem às concepções por eles sustentadas sobre a suficiência do domínio de conteúdos científicos para atuar nas atividades, visto que se depararam em alguns momentos com obstáculos à interação com os visitantes. Neste sentido, uma atitude inquiridora requer que o monitor supere a insegurança e desafie a si mesmo quanto às suas dificuldades; por isso, entendemos que a formação possa recorrer a atividades destinadas a superar dificuldades de interação com o público, conduzindo visitas através de perguntas e questionamentos numa espécie de maiêutica socrática, a fim de iniciar o diálogo para melhor exploração das ideias e reconstrução de pensamentos [35, 36]. Apesar disso, a postura inquiridora do monitor nem sempre é desejada pelo próprio público e pode haver situações que os visitantes prefiram um monitor enquanto explicador, isto é, podem acontecer situações em que o visitante queira apenas observar um objeto ou exposição, perguntar e ouvir do monitor explicações sobre os conteúdos associados a ela e prosseguir em seu trajeto por aquele local [15].

Isso indica que as posturas e atitudes do público em meio às visitas podem variar de acordo com o que ele experimenta e as expectativas que possui. Nessas situações, o monitor precisa estar atento às reações dos visitan- 
tes, buscando levantar questões motivadoras e "articular um discurso comum do grupo mediado por ele" [18]. Como destacado por Dutra e colaboradores (2010) [17], ao constatar entre alguns visitantes uma insatisfação, é importante que o monitor desenvolva estratégias que aumentem as expectativas do público, "acrescentando fatos interessantes sobre o que se vê" [17], além de "incluir novos fatos ou histórias" (Ibid.). Os autores mencionam como exemplo de aplicação dessas estratégias, uma situação específica de intervenção dos monitores numa atividade de observação do céu.

Uma pessoa do público, estudante de Ensino Médio, ficou frustrada ao ver Júpiter como uma pequena bolinha ao telescópio, muito menor que as fotos que aparecem nos livros didáticos. Porém, ao introduzirmos a informação de que Júpiter é cerca de mil vezes maior que a Terra e de que as quatro "estrelas"que ele estava vendo ao redor do planeta eram na verdade quatro, de suas mais de sessenta luas, fez com que fossem criadas novas expectativas. O estudante voltou a olhar com empolgação para o telescópio questionando sobre a distância entre Júpiter e a Terra e como seria olhar para o céu em Júpiter e observar várias luas na mesma noite [17].

Ao assumir uma conduta explicadora ou inquiridora de acordo com a ocasião, o monitor demonstra sensibilidade aos diferentes perfis de público que atende, de modo que a pluralidade de públicos acaba também sendo favorável a uma pluralidade de posicionamentos por ele assumidos, enriquecendo assim a sua experiência. Do ponto de vista de auxiliar o público visitante a compreender a atividade (uma exposição de astrofotografias ou observação astronômica, por exemplo), poderíamos afirmar que o monitor tende a contribuir para uma "mudança da percepção" do público "em relação à forma", cuja interação entre ambas as partes faz com que o visitante passe a ver a atividade a partir de outros ângulos.

O modelo de formação dos monitores do Observatório é predominantemente da relação aprendiz e mestre, conforme reflexões de Marandino (2008) [14]. Percebe-se também um elemento de autoformação, em que os monitores buscam enriquecer a prática a partir da busca própria de conhecimento, seja em fontes bibliográficas seja em eventos e outras programações.

Diante dos dados discutidos, percebemos o papel da monitoria centralizado no aprendizado de conteúdos conceituais de astronomia, ficando claro em vários momentos ao se valorizar e priorizar o domínio desses conceitos, seja como recurso para aprimoramento do seu papel ou como experiência proporcionada pela monitoria, isto é, sustenta-se a visão de que "basta o conteúdo" para atuar como monitor. Por outro lado, foram encontradas muitas dificuldades de interação com o público esbarradas pelos monitores, mostrando como a comunicação acaba se tornando um desafio relevante a lidar. É o público, portanto, que provoca o monitor, e o faz mobilizar estratégias e atitudes que vão além da exposição de conteúdos e conceitos.

Do ponto de vista da formação, como é possível enfatizar essa questão? Quais aspectos poderiam delinear o perfil de um monitor que viessem a satisfazer as necessidades do público? Primeiramente, nos atendimentos escolares, entendemos a necessidade de preparação das visitas por parte das instituições de ensino que agendaram a visita, em parceria com a instituição que irá visitar e, assim, monitor planejaria a sua atuação com esse público conforme as informações fornecidas durante o agendamentd 18 É fundamental também que a instituição assuma a importância de orientar a formação de seus monitores seja em relação aos conteúdos conceituais, seja na perspectiva da interação com o público, enfatizando os aspectos de educação e comunicação.

Por fim, é interessante destacar a preocupação demonstrada por alguns monitores com a falta de bolsas, como um problema que eles se deparam e que acaba sendo desestimulante para dedicação efetiva no Observatório. Neste sentido, compreendemos que o apoio financeiro através de remuneração (bolsas, vínculo empregatício, etc.) é fundamental para a dedicação efetiva do monitor à formação [13], ao passo que "em locais onde monitores não têm condições financeiras para mantimento, a monitoria remunerada vem a se tornar um recurso favorável à permanência do mesmo no curso de graduação" [3].

A partir dos dados analisados, explanados e discutidos neste artigo, procuramos apresentar a seguir os elementos teóricos daquilo que entendemos assumir o perfil de um monitor atuante em um observatório astronômico. Esse perfil é dividido em dois locais: 1) atuação em campo, nos atendimentos ao público (Tabela 1) e; 2) atuação interna, no local de trabalho (Tabela 2).

Essas características têm em comum o fato de serem notadas durante atividades com o público nas quais o monitor troca experiências e agrega saberes, contorna dificuldades e aprimora a sua prática através de uma formação permanente. No caso de observatórios astronômicos, porém, é comum que monitores assumam a responsabilidade em outros setores que não estão necessariamente relacionados às atividades com o público, como identificado na Tabela 2, a seguir.

\section{Considerações finais}

Atividades realizadas nos espaços de divulgação da Astronomia têm o potencial de direcionar a atenção dos visitantes para a monitoria, dado o aspecto motivador presente nos atendimentos desses locais. Pudemos constatar este fato nos relatos de alguns monitores participantes da pesquisa, que mencionaram programações realizadas

\footnotetext{
18 Exemplos: a) escolaridade dos visitantes; b) experiências anteriores com observatórios; c) temas de interesse da Astronomia; d) expectativas dos visitantes quanto à visita, entre outras.
} 
Tabela 1: aspectos relativos ao perfil do monitor em sua atuação em campo, nos atendimentos ao público. Fonte: própria pesquisa.

\begin{tabular}{|c|c|}
\hline Item & Características \\
\hline Prática do monitor & $\begin{array}{l}\text { - Prática do monitor novato baseada na experiência do monitor veterano. } \\
\text { - Levantamento de informações entre o público que permitam nortear a atividade. } \\
\text { - Retorno positivo do público como elemento motivador à prática. } \\
\text { - Ação do monitor para mudança da percepção do público sobre a exposição. } \\
\text { - Levantamento de perguntas motivadoras. } \\
\text { - Conhecimento do local em que irá atuar (estrutura e atividades). } \\
\text { - Necessidade de atualização dos assuntos divulgados pela mídia. }\end{array}$ \\
\hline $\begin{array}{l}\text { Habilidades proporcionadas pela } \\
\text { monitoria }\end{array}$ & - Superação de dificuldades ao lidar com diferentes públicos \\
\hline Formação & $\begin{array}{l}\text { - Conhecimento do monitor recém-chegado por parte da instituição. } \\
\text { - Monitoria com o objetivo de superação de defasagens educacionais. } \\
\text { - Grupo de estudos local como espaço formativo. } \\
\text { - Produçãa de materiais de ensino e divulgação. } \\
\text { - Busca de cursos de extensão complementares. } \\
\text { - Participação em projetos interdisciplinares complementares. } \\
\text { - Relacionamento entre equipe. }\end{array}$ \\
\hline
\end{tabular}

Tabela 2: Aspectos relativos ao perfil do monitor em atuação interna, no local de trabalho. Fonte: própria pesquisa.

\begin{tabular}{|c|c|}
\hline Natureza da função & Características \\
\hline Administrativa & $\begin{array}{l}\text { - Organizar reuniões entre equipe; } \\
\text { - Entrar em contato com instituições para agendamento/remarcação/cancelamento de visitas; } \\
\text { - Representar a equipe em eventos de divulgação científica em que o observatório participar } \\
\text { (mostras científicas, exposições, feiras de ciências, etc.); } \\
\text { - Representar a equipe em reuniões internas da instituição (departamentos); }\end{array}$ \\
\hline Técnica & $\begin{array}{l}\text { - Gerenciar o empréstimo de obras e títulos do acervo bibliográfico do local; } \\
\text { - Auxiliar no gerenciamento financeiro do local; } \\
\text { - Gerenciar e administrar os mecanismos de comunicação do local: redes sociais, sites e outros } \\
\text { canais de divulgação; } \\
\text { - Elaborar documentos utilizados no observatório: formulários, planilhas, registros de inventário, } \\
\text { etc.; }\end{array}$ \\
\hline Organizacional & $\begin{array}{l}\text { - Organizar os materiais e instrumentos nos locais adequados; } \\
\text { - Realizar limpeza do local; } \\
\text { - Checar periodicamente o estado de conservação de materiais e equipamentos, a fim de encontrar } \\
\text { possíveis problemas ou falhas para corrigir; }\end{array}$ \\
\hline De Ensino & $\begin{array}{l}\text { - Produzir materiais didáticos de ensino de astronomia de apoio ao professor: apostilas, unidades } \\
\text { temáticas, tutoriais, oficinas, entre outros; } \\
\text { - Elaborar materiais informativos sobre o observatório: folhetos, boletins, formulários, etc.; }\end{array}$ \\
\hline De Pesquisa & $\begin{array}{l}\text { - Efetuar diagnóstico entre o público sobre as principais concepções e dificuldades para o aprendizado } \\
\text { da astronomia; } \\
\text { - Efetuar análise da sua prática, enquanto monitor, especificando os obstáculos encontrados e as } \\
\text { possíveis alternativas; } \\
\text { - Efetuar levantamento sobre o ensino de astronomia no entorno do local em que atua, situando o } \\
\text { observatório como espaço de apoio à superação de possíveis lacunas; } \\
\text { - Buscar elementos teóricos e práticos que fundamentem sua atuação como monitor a partir da } \\
\text { educação em astronomia, educação não formal e divulgação científica. }\end{array}$ \\
\hline
\end{tabular}

pelo observatório como importantes para motivá-los à monitoria e que incluem não somente os atendimentos escolares e ao público, mas também os cursos de extensão, oficinas e outras atividades que acabam se tornando "recrutadores" de novos alunos interessados, além de influenciar o visitante na escolha de carreiras e cursos universitários.

No que concerne à formação localmente vivenciada, verificamos a predominância do modelo nomeado por Marandino (2008) [14] como aprendiz e mestre. Não apenas os monitores novatos, mas outros que estão há mais tempo se baseiam na experiência dos veteranos para aperfeiçoar a prática nas atividades. Outro modelo identificado foi o de formação na prática, pois é na experiência que o monitor tem com o público que ele se forma, e assim esta funciona como um "termômetro" para sua atuação, além de agregar novas habilidades ao monitor, ensinando-o a lidar com diferentes contextos que permitam a superação da insegurança. Diante deste panorama, é possível afirmar que uma formação apenas baseada em um modelo conteudista ou deixando na mão do próprio monitor seu processo formativo não dá conta de suprir as necessidades do monitor e da relação dos Observatórios com a sociedade, visto que este acaba se pautando em um ensino tradicional, baseado na transmissão verbal de conceitos e memorização mecânica [37].

Diante das reflexões pontuadas até aqui, pensamos que seja necessário, que espaços como observatórios definam precisamente qual é o papel do monitor e qual o perfil ele deve possuir para exercer as atividades nesses 
locais. É imprescindível, neste caso, que essas concepções sejam organizadas em documento análogo a um "projeto político-pedagógico", destinado a fundamentar o programa local de formação dos seus monitores. Os aspectos da educação não formal e da divulgação científica, articulados com os conceitos da astronomia e ensino, também necessitam estar imbricados a esse projeto, dado que são eles os elementos fundacionais que orientarão a atividade do monitor, ao mesmo tempo em que os contornos característicos do local deverão permear todo o processo.

Acreditamos que a estruturação de programas de formação pode conferir maior identidade ao papel de monitor ao satisfazer as exigências e encargos assumidos por ele, podendo assim contribuir para melhoria das suas condições de trabalho e remuneração. Neste sentido, a formação inicial pode considerar parcerias com observatórios para realização da prática pedagógica, articulando-se disciplinas da área de ensino e educação para o desenvolvimento de atividades sob esse enfoque. Pode-se ainda estruturar disciplinas optativas de divulgação científica voltadas para observatórios astronômicos e planetários. Entendemos que seja importante a estruturação de uma formação incumbida por profissionais, pesquisadores envolvidos diretamente com a divulgação científica, educação não formal, astronomia e ensino de astronomia. Além disso, o grupo de estudos pode ser uma oportunidade para ir além da formação em conceitos da astronomia e de ensino ao se transformar em uma oportunidade para os monitores apresentarem as dificuldades e trocar experiências entre colegas que favoreçam o engajamento em equipe. Do ponto de vista do monitor como iniciante à pesquisa acadêmica [25], uma estratégia de formação continuada consiste na realização de minicursos e participação em eventos da área que, analogamente às escolas de formação de professores, possam ser desenvolvidas escolas de formação de monitores para divulgação da Astronomia em eventos da área, como o SNEA ${ }^{19}$ ou reuniões e encontros anuais da $\mathrm{SAB}^{20}$ e $\mathrm{ABP}^{21}$

Ainda são poucos os espaços não formais que promovem a formação de monitores, evidenciando um cenário precário no desenvolvimento de ações educativas nessas instituições, marcado sobretudo pela má remuneração e volatilidade do vínculo do monitor. Contudo, a partir da experiência local por nós investigada, compreendemos a monitoria como uma experiência bastante proveitosa que pode enriquecer a formação do monitor ao agregar habilidades, técnicas e conhecimentos que constituem sua trajetória profissional.

\section{Referências}

[1] G. Queiroz, S. Krapas, M.E. Valente, E. David, E. Damas e F. Freire, Rev. Bras. Pesq. Ed. Ciên. 20, 77 (2002).

\footnotetext{
19 Simpósio Nacional de Educação em Astronomia.

20 Sociedade Astronômica Brasileira.

21 Associação Brasileira de Planetários.
}

[2] C. S. da Silva, Formação e Atuação de Monitores de Visitas Escolares de um Centro de Ciências: Saberes e Prática Reflexiva. Dissertação de Mestrado, UNESP, 2009.

[3] L.G. Barros e R. Langhi, in: Anais do IV Simpósio Nacional de Educação em Astronomia, Goiânia, 2016, p. 35.

[4] I. Gomes e S. Cazelli, Ensaio 18, 23 (2016).

[5] J.B.V. Marques, Educação Não-Formal e Divulgação de Astronomia no Brasil: O que Pensam os Especialistas e o que Diz a Literatura. Dissertação de Mestrado, UFSCar, 2014.

[6] L.G. Barros, Um Estudo Sobre a Formação de Monitores em Espaços de Divulgação da Astronomia. Dissertação de mestrado, UNESP, 2017.

[7] M. Marandino, Cad. Bras. Ens. Fís, 18, 85 (2001).

[8] R. Strack, R. Loguércio e J.C. Del Pino, Ciên. \& Ed. 15, 425 (2009).

[9] R. Langhi e R. Nardi, Rev. Bras. Ens. Fís. 31, 4402 (2009).

[10] A.L. Grinder and E.S. McCoy, The Good Guide: A Sourcebook for Interpreters, Docentes and Tour Guides (Ironwood Publishing, Scottsdale, 1989).

[11] A. Bizerra and M. Marandino, in: Anais do VIII Encontro Nacional de Pesquisa em Educação em Ciências, Aguas de Lindoia, 2011.

[12] C. Carletti and L. Massarani, J. Sci. Com. 14, 1 (2015).

[13] C. Carletti, Mediadores de Centros e Museus de Ciência: Um Estudo Sobre Quem São Estes Atores-Chave na Mediação entre a Ciência e o Público no Brasil. Tese de doutorado, Fiocruz, 2016.

[14] M. Marandino, in: Workshop Sul-Americano de Mediação em Museus de Ciência, editado por M. Massarani and C. Almeida (Museu da Vida / Casa de Oswaldo Cruz / Fiocruz, Rio de Janeiro, 2008), p. 21.

[15] F. Brito, in: Workshop Sul-Americano de Mediação em Museus de Ciência, editado por M. Massarani and C. Almeida (Museu da Vida / Casa de Oswaldo Cruz / Fiocruz, Rio de Janeiro, 2008), p. 37.

[16] S. Cazelli, C.A.Q. Coimbra, M. Vergara, A. Costa, D. Falcão and M.E. Valente, in: Workshop Sul-Americano de Mediação em Museus de Ciência, editado por M. Massarani and C. Almeida (Museu da Vida / Casa de Oswaldo Cruz / Fiocruz, Rio de Janeiro, 2008), p. 61.

[17] G. Dutra, S.A. Fernandes, R.S. Araujo e C.B.M. Pigozzo, in: Anais do XIII Encontro Nacional de Astronomia, Recife, 2010.

[18] D.V. Bevilaqua, in: Educação e Cultura Científica e Tecnológica: Museus e Centros de Ciências no Brasil, editado por C.R. Borges, A.L. Imhoff e G.B. Barcellos (EDIPUCRS, Porto Alegre, 2012), p. 247.

[19] L. Standerski, Relatório Final de Iniciação Científica FAFE/FEUSP, 2007.

[20] C.S. da Silva e L.A.A. Oliveira, Ensaio 13, 47 (2011).

[21] A.P. Jeakel, M. Siman e G. Camiletti, in: Anais do XXI Simpósio Nacional de Ensino de Física (SBF, Uberlândia, 2015), p. 121.

[22] M.P.O. Bonatto, M.I. Seibel e I.A. Mendes, in: Diálogos \& Ciência: Mediação em Centros e Museus de Ciência, editado por L. Massarani (Museu da Vida / Casa de Oswaldo Cruz / Fiocruz, Rio de Janeiro, 2007), p. 48. 
[23] D.F.B. Ovigli, D. Freitas e J.J. Caluzi, in: Ensino de Ciências e Matemática (IV): temas de investigação, editado por N. Pirola (Cultura Acadêmica, São Paulo, 2010), p. 95.

[24] D.F.B. Ovigli, Ensaio 13, 133 (2011).

[25] J.A. Gomes, Relatório Final de Iniciação Científica FAFE/FEUSP, 2008.

[26] U. Flick, Introdução à Pesquisa Qualitativa (Artmed, Porto Alegre, 2009), 3 ed.

[27] A.M.P. Carvalho, in: A Pesquisa em Ensino de Ciências no Brasil e suas Metodologias, editado por F.M.T. Santos and I. Greca (Editora da Unijuí, Ijuí, 2012), p. 13.

[28] H.M. Vianna, Testes em Educação (IBRASA, São Paulo, 1976).

[29] M.L.P.B. Franco, Análise de Conteúdo (Liber Livro Editora, Brasília, 2005).

[30] L. Bardin, Análise de Conteúdo (Edições 70, Lisboa, 2009).

[31] V. Daelli and P. Rodari, CAP Journal 16, 28 (2014).

[32] A. Pugliese, Os Museus de Ciências e os Cursos de Licenciatura em Ciências Biológicas: O Papel Desses Espaços na Formação de Frofessores. Tese de Doutorado, USP, 2015.

[33] C.W.A. Caffagni and M. Marandino, in: Educação e Cultura Científica e Tecnológica: Museus e Centros de Ciências no Brasil, editado por C.R. Borges, A.L. Imhoff e G.B. Barcellos (EDIPUCRS, Porto Alegre, 2012), p. 225.

[34] M.G. Ribeiro, in: Diálogos \& Ciência: Mediação em Centros e Museus de Ciência, editado por L. Massarani (Museu da Vida / Casa de Oswaldo Cruz / Fiocruz, Rio de Janeiro, 2007), p. 67.

[35] C.A. Padesky, in: European Congress of Behavioural and Cognitive Therapies, London, 1993, p. 1.

[36] A.C. Panzera and S.P. Thomaz, Fundamentos de Astronomia: Uma Abordagem Prática Para o Ensino Fundamental (CeciMig, Belo Horizonte, 1995).

[37] R. Langhi e R. Nardi, Educação em Astronomia: Repensando a Formação de Professores (Escrituras Editora, São Paulo, 2013). 